\title{
Regional Demographic Differences: the Effect of Laestadians
}

\author{
EMMA TERÄMÄ, Ph.D., Research Fellow \\ University of Amsterdam, Amsterdam Institute for Social Science Research \\ The Netherlands \& \\ Finnish Environment Institute, Environmental Policy Centre,Helsinki, Finland
}

\begin{abstract}
Laestadianism, a conservative revival movement inside the Lutheran church, has an estimated 100,000 followers in Finland. Laestadians have characteristics differing from the followers of the mainstream state church in areas such as religious activity, regional concentration, fertility and family planning, but these are generally not quantified due to lack of easily accessible data. This study highlights the importance of including location and religiosity, and not only religious affiliation in the study of fertility behaviour. The research uses statistical tools to study the correlations between such variables as religious density and total fertility rate. It is found that on the regional level, the total fertility rate and the increasing number of small children in the family is positively associated with the proportion of Laestadians. The regional variation of religiousness, and the subsequent effects on population structure and socioeconomics are discussed.
\end{abstract}

Keywords: Laestadians, religiosity, high fertility population, minority

\section{Background}

Communities that share a tradition of faith and values may differ significantly in their demographic histories. This is attested by a wealth of empirics on religious differences in fertility (Frejka and Westoff 2006, Derosas and van Poppel 2006, McQuillan 2006). This study addresses regional fertility differences, and the role of the religious minority of Laestadians in creating it. Location and religiousness are shown to be influential elements in discussing the evolving patterns of the demography of regions.

Finland is still rather homogeneous in terms of its population composition. For example in 2007, by religious denomination over 80 percent of the 5.3 million population were Lutheran (Kääriäinen at al. 2008). The next biggest denomination is Orthodox Christian, with some 58,000 followers, and Jehova's witnesses with under 20,000 followers. In terms of nationalities, Finland is also one of the most homogeneous countries in Europe, with only 2.5 percent of its population being of foreign origin at the end of 2007 (Kääriäinen at al. 2008). 
Location and religious affiliation are often coupled. Countries have been made and destroyed based on religious beliefs, not to mention provinces, municipalities, cities and communities. People belonging to minorities form spatial sub-communities in order to support one another on the one hand, and to decrease outside influence on the other. To survive, they need successful biological investment (fertility-survival) and the capacity to transfer enough symbolic capital (such as language, religion, and customs) from generation to generation (Oris et al. 2005).

There has recently been a decline in the study of religious affiliation as a determinant of demographic behaviour, as a result of the smaller religious differences in parity (Mosher et al. 1992, McQuillan 2004, Philipov and Berghammer 2007). With the levelling off of the old Catholic-Protestant fertility differentials, a new era of religion inspired population research is surfacing, namely that of cultural beliefs and practices (Goujon et al. 2007, Philipov and Berghamer 2007, Lutz et al. 2006).

As the main religious groups throughout Europe have come closer to each other in terms of their fertility behaviour, other distinctively differing groups have begun to emerge. One is the increasing minority of Muslims, who, in Finland, have immigrated to a great extent as asylum seekers, and are but a few. The other important groups are religious fundamentalists and revivalists. In addition to movements and cultural groups, frequently attending followers of any mainstream religion could be classified as minorities based on their beliefs, intensity, and presumably distinctive fertility behaviour.

Minorities and their fertility behaviour have also been studied for several decades. Goldscheider and Uhlenberg conclude already in 1969 that a minority group status will operate to enhance the fertility differential with respect to the majority group when committed to a religious ideology or socio-cultural norm that encourages large families and/or restricts the choice and use of contraception (Goldscheider et al. 1969). Otherwise, they find that the fertility levels of a minority group are depressed, perhaps as a result of the insecurities associated with minority group status.

Voas (2007) and Zhang (2008) find that in fact religiosity rather than religious identity may be the key in discovering the modern connections between population studies and religion. Similarly, Jewish studies in the past have shown a remarkable difference in fertility depending on religiosity, rather than religious affiliation. Mott and Abma (1992) conclude that Orthodox Jews have substantially more children than the Jewish majority despite belonging to the same church. Philipov and Berghammer (2007) found in their international study that the attendance of religious services has a strong impact on fertility ideals, and confirm that the measure is a slightly more relevant predictor of such ideals than affiliation alone. In addition, a higher intensity of selfassessed religiosity is positively associated with the measures of fertility (Philipov and Berghammer 2007). With the progressive loss of influence of religious institutions in 
the society, the degree of church attendance has become a more salient predictor of family norms, particularly for women (Adsera 2006).

Although religious minorities, e.g. revivalists are often public and commonly known, the number of followers and the intensity of their religiousness is a different question. Surveys and census information on such groups are scarce, in part due to the very fact that the branches may still be affiliated with their church of origin, like is the case with the Laestadians. This study attempts to combine fertility differentials with not only religious affiliation of the population, but sub-affiliation (revival movement), religiousness and spatial distribution.

\section{Laestadians of Finland}

A historical account for how Laestadianism has evolved has been documented earlier (Lohi 1997). However, in the context of religious minorities, little has been written about Laestadianism. This is surprising, since in terms of estimated numbers of followers, Laestadianism is a minority much bigger than other (registered) denominations, after the state church. It is generally believed that the different branches of Laestadianism have differing trends in their stand and recommendations concerning e.g. family planning. This article focuses on one of several branches, namely the Conservative Laestadians, who also make up the majority of Laestadians in Finland. Perhaps unsurprisingly, they are also known as the most conservative branch of the movement. Without plunging deeper into the ideology of the Laestadians, it is assumed that compared to the followers of the mainstream Lutheran denomination, the Laestadians are a religious people. They have chosen a revival movement to guide their path, and with it, a set of more rigid guidelines than imposed upon the followers of the mainstream church. Abiding to such guidelines will undoubtedly show in demographic analysis, and as this study points out, even in a regional analysis provided the concentration of the population with distinctive fertility behaviour is substantial. In the absence of a better measure, the density of (Laestadian) churches is assumed a cue for high fertility in a region. For the purpose of this article I refer to the Conservative Laestadians as simply Laestadians. A Laestadian is someone who belongs to the Lutheran church and practises Laestadian faith.

The revival movements inside the state church are not documented separately in the population registry. Since the Laestadians belong to the Lutheran church, detailed information about the demographic composition of those participating in the movement is not available. Perhaps due to data restriction, this revival movement has been much overlooked in studies of religious fertility and minority fertility differentials in the past. The people of Laestadian faith can nevertheless have a strong impact on the local development and demography of their town, municipality, even region. Their religion is known for its natural fertility emphasizing family values and guidelines 
including pre-marital abstinence and refraining from the use of contraception. However, belonging to a religious group no longer equals adhering to all the teachings and recommendations provided by the group. For a measure of how religious a person is, we need to quantify religious intensity, or religiosity. Quantifying religiosity, however, is challenging, e.g. when coupled to the study of (marital) fertility, including inter-faith couples (Neuman 2007).

The concept of religiosity and adhering to religious guidelines is particularly interesting in contemporary Finland, where increasingly secular and non-religious values lead to more and more people leaving the church (Käariäinen et al. 2008). It has been shown that religious affiliation alone is an insufficient measure in explaining current fertility patterns and norms. Laestadians are an example, belonging to the state church, but having characteristicly different fertility behaviour from the majority.

Local fertility behaviour has been under scrutiny in Finland before. In 1991 an article was published in Population Studies that highlighted the demographic development of a small town of some 3500 inhabitants, namely Larsmo - Luoto (Finnäs 1991). In this article, Finnäs describes a population of pro-natalists living in a rather closed community. He describes a town with an approximated $40 \%$ Laestadian population, and a total fertility rate (TFR) as high as 3.68 around 1980 (cf. average TFR of 1.63 for Finland that year). Based on his research of historical church records, he concludes that whereas the TFR of Finland started to decline steeply in early 1960s, the pattern did not apply to Larsmo. Before the 1960s, the total fertility rate was well above 2.5, and plummeted to 1.5 in 1973, from which it has slowly recovered to the current levels of about 1.85 (Statistics Finland 2010). Comparing to Hutterites, the small Protestant group in North America often quoted for their natural fertility (e.g. Espenshade 1971), Finnäs finds a differing pattern of parity among the Laestadians. The Hutterite distribution of women by parity is unimodal with the modal number between nine and eleven. For the Laestadian women the distribution is bimodal with peaks at four and ten. That is to say, the Hutterite women produce on average nine to eleven children whereas the Laestadians may have a smaller family of four, or conversely a larger family of ten children. Laestadians therefore do not exhibit a fully natural fertility pattern, but have nevertheless a much higher fertility than the average Finn.

\section{Other religious minorities and locations}

Well-known examples of closed communities are religious ones, like the Amish, in the United States. The Amish often appear in studies of religious fertility differentials. A comparison is provided by the Hutterites, as mentioned above. Ericksen et al. publish a (by now) historical account of Amish and Hutterite fertility, and make comparisons to the American average (Ericksen et al. 1979). They, too set out to investigate whether there had been changes in the fertility behaviour of the Amish (cf. Finnäs, above). His- 
torically, it can be seen that the maintenance of high fertility norms of the Amish results in a high rate of population increase, of which one manifestation could be the steep increase in number of church districts in Lancaster County (Ericksen et al. 1979).

Socioeconomic status does not necessarily have a negative impact on fertility, argues Heaton (1986) in the case of Mormons, and goes on to say that the acceptance of the Mormon theology of marriage, contact with other Mormons as a reference group, and socialization in a Mormon subculture all have a positive influence on their fertility. The pattern of high fertility depicted by Mormons in e.g. Utah, USA, strengthens the local interdependence between religion and family much in the same way as is investigated here in the case of Laestadians.

Other religious communities, such as the Catholic, have been both leaders and laggards in the demographic transition, depending on location (van Heek 1956, McQuillan 2004). The same is true in the Muslim world. Islam is widely associated with persistently high fertility, however in certain countries, such as Turkey, Tunisia and Lebanon, it has not stood in the way of fast declining fertility in the latter part of the $20^{\text {th }}$ century (Obermeyer 1992, 1994).

Muñoz (2009) studies the geographies of religion and ethnicity in the context of three different kinds of Indian faith in Scotland. She concludes that religion, not only ethnicity, plays a role in determining contemporary residential patterns and levels of segregation (Muñoz 2009). She finds that there is inherent value in incorporating religious affiliation into the study of geographies of population.

\section{Data and methods}

As the exact numbers of followers of the Laestadian revival movement are not known, much less so by region or municipality, it is difficult to formulate a "bigger picture" of how a community with preferences for restricting family planning and use of contraceptives affect local demography. Based on municipality and regional level population data, as well as surveys on beliefs, the effect of the fertility behaviour that was observed by Finnäs (1991) is investigated to this day. Regional level religiousness is coupled to fertility, and it is proposed that the mere existence of several religious places of worship is a sign of concentrated religious intensity and population growth, as introduced by Ericksen et al. (1979).

To obtain some location specific measure of Laestadian activity, a list of the membership totals of 188 current local Laestadian congregations was obtained. One of the data sources is thus a membership listing from 2008 by the Central Committee of Conservative Laestadian Congregations ${ }^{1}$ (SRK 2010). The total number of members of each local congregation only includes the number of adults, in this case, over 15-year-olds.

1 www.srk.fi 
In addition, this study is based on several other data sources. One is a survey conducted in 2004, namely the "Church Monitor" (Kääriäinen 2007). This is a survey with $N=2569$ adult respondents, ages 15 and above, depicting the decline, change and transformation of Finnish religiosity, and involves the Research Institute of the Evangelical Lutheran Church of Finland. Another source is a survey conducted by the Evangelical Lutheran Church periodically every four years, directed at the clergy and the congregations (Kääriäinen et al. 2008). The final data source is derived from Statistics Finland ${ }^{2}$, the only Finnish public authority for statistics. Statistics Finland provides data on population on various geographical levels and measures, as well as on economic indicators. This data is used to compare and highlight regional demographic and socioeconomic differences. The data sources are together chosen to establish a base for estimating the intensity and locating the activity of the Laestadian church in Finland, and to compare to regional level population and socioeconomic data.

The applied methodology is essentially descriptive statistics. Hypothesis testing and statistical significance were applied to evaluate the momentousness of the survey results for the case of Laestadians, who represented a minority in the sample(s). Simple linear regression is used to investigate correlations between relevant datasets, hereby providing evidence of concurrence. The dependent variables are total fertility rate and two measures of family size, namely families with $4+$ minor children, and families with $3+$ children under the age of seven. These data are available in 2008 for all NUTS 3 regions in Finland. The main independent variable is the share of active Laestadians of the total local adult (age $>15)$ population.

\section{Results}

In terms of the Nomenclature of Territorial Units for Statistics, or NUTS, mainland Finland is divided into nineteen NUTS 3-size regions, as shown in Figure 1

2 www.stat.fi 


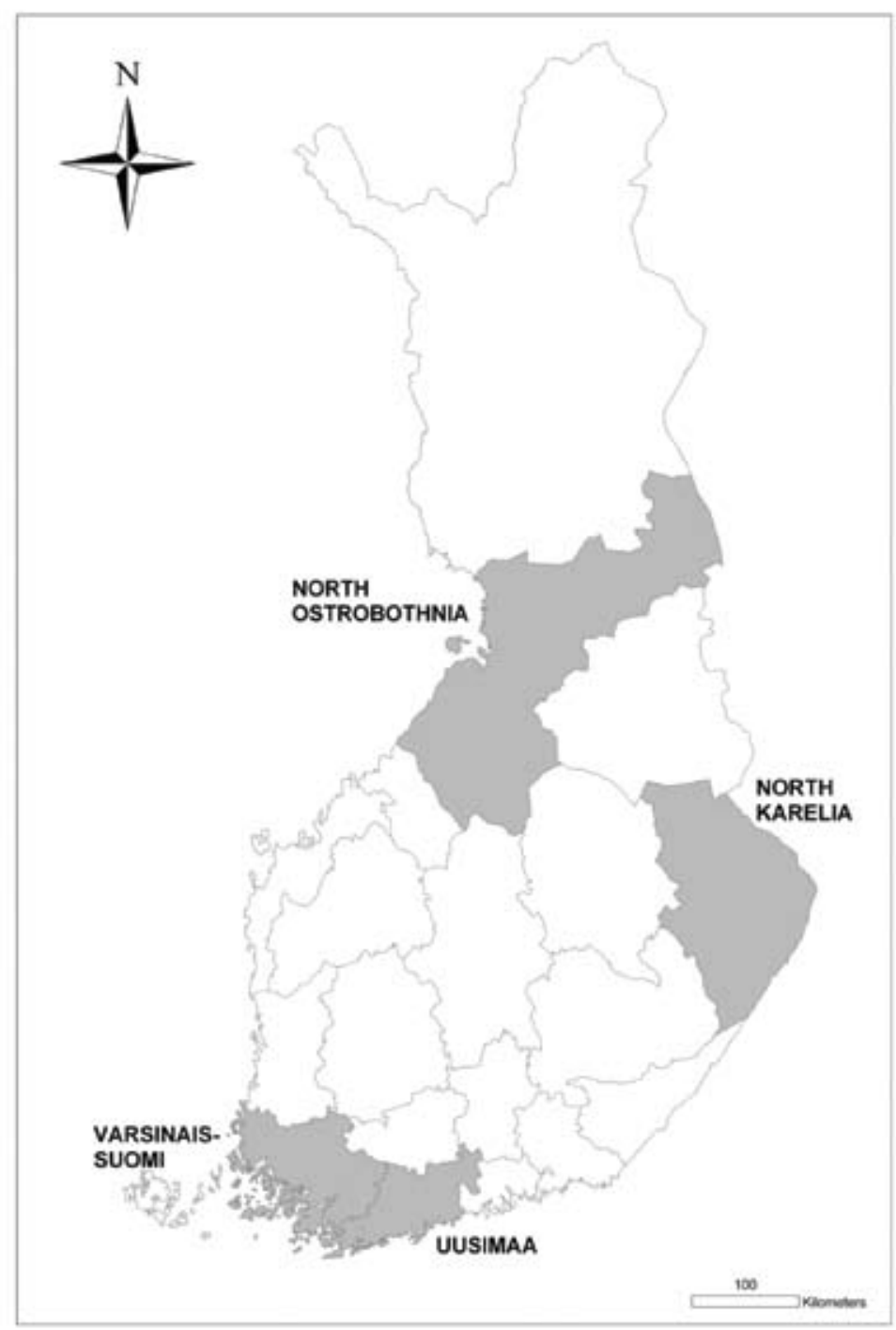

Figure 1. Finland with regional borders.

Hereafter the term 'region' refers to this size index. The nineteen regions vary a great deal in terms of population size, density and structure. Figure $2 \mathrm{a}-\mathrm{d}$ shows the population pyramids of four regions, selected based on different population structure, geographic location and socioeconomic affluence, see e.g. Heikkilä and Pikkarainen (2010) for a discussion of economically competitive regions and causes in Finland. Note the especially large difference at the base of the pyramids 
Figure 2 a-d. Population by gender and five-year age groups of selected NUTS 3 regions in 2008 (Statistics Finland).

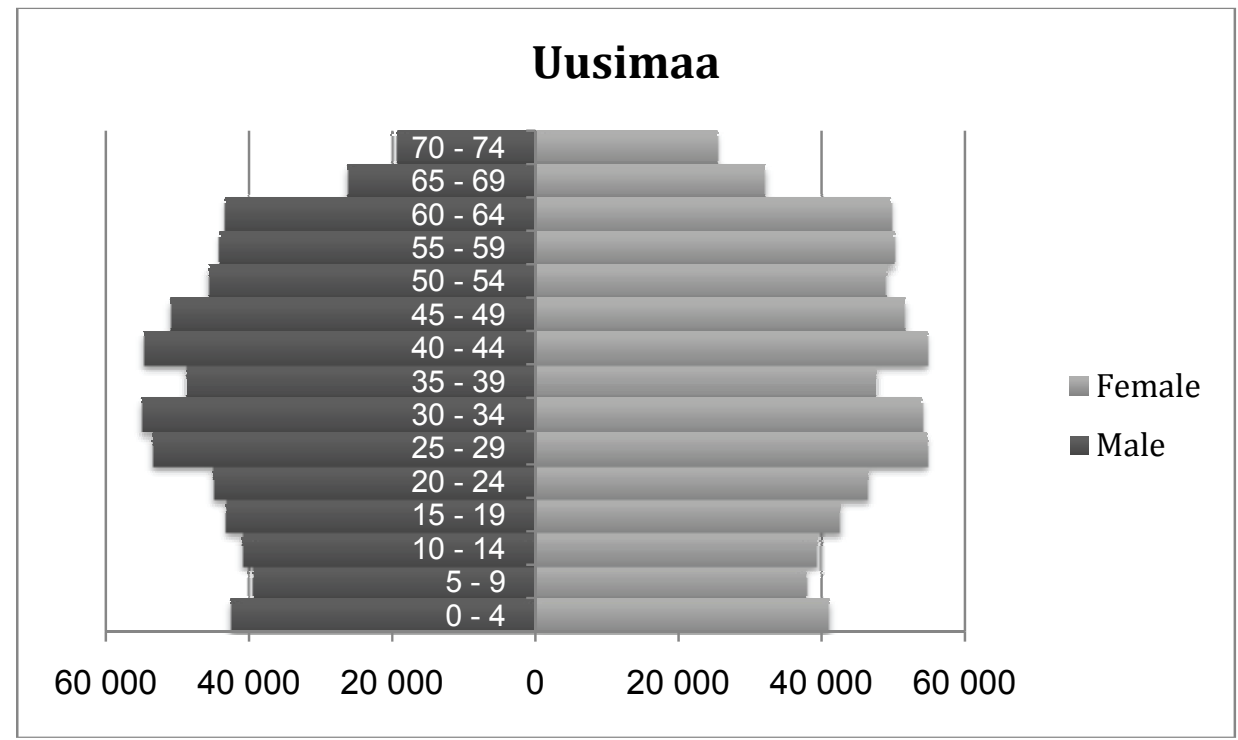

Figure 2 a

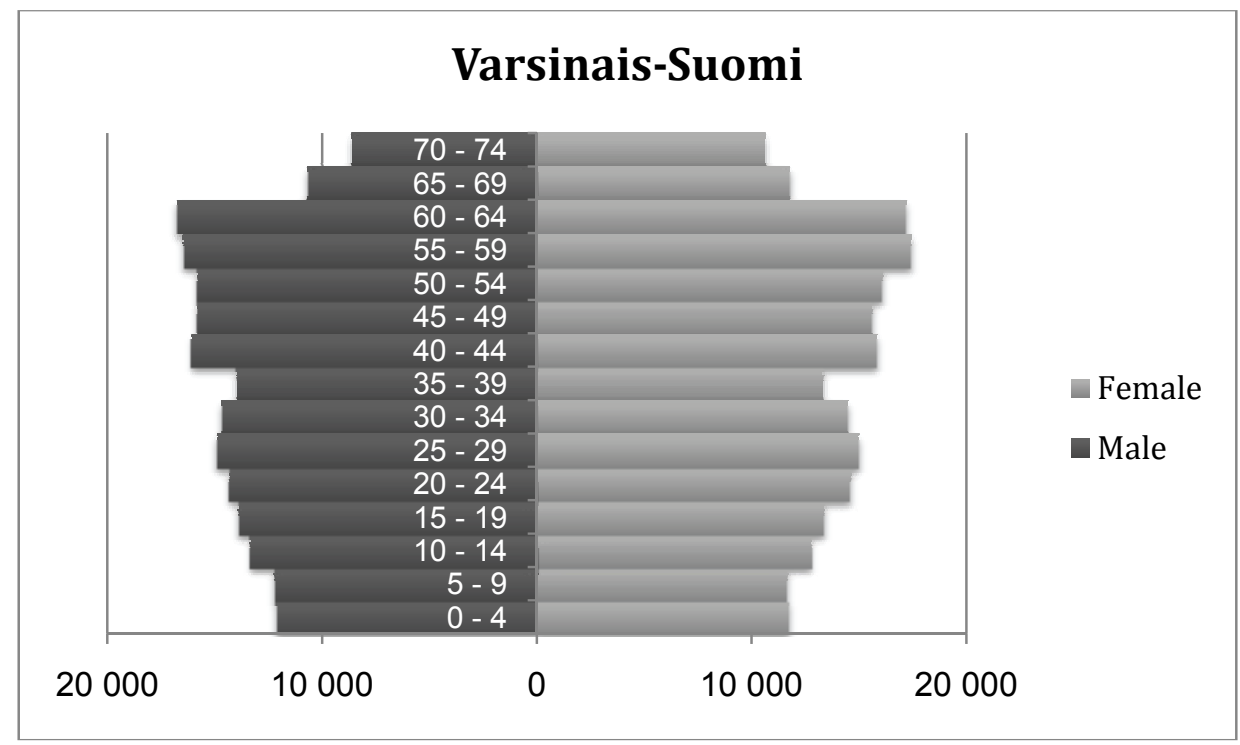

Figure 2 b 


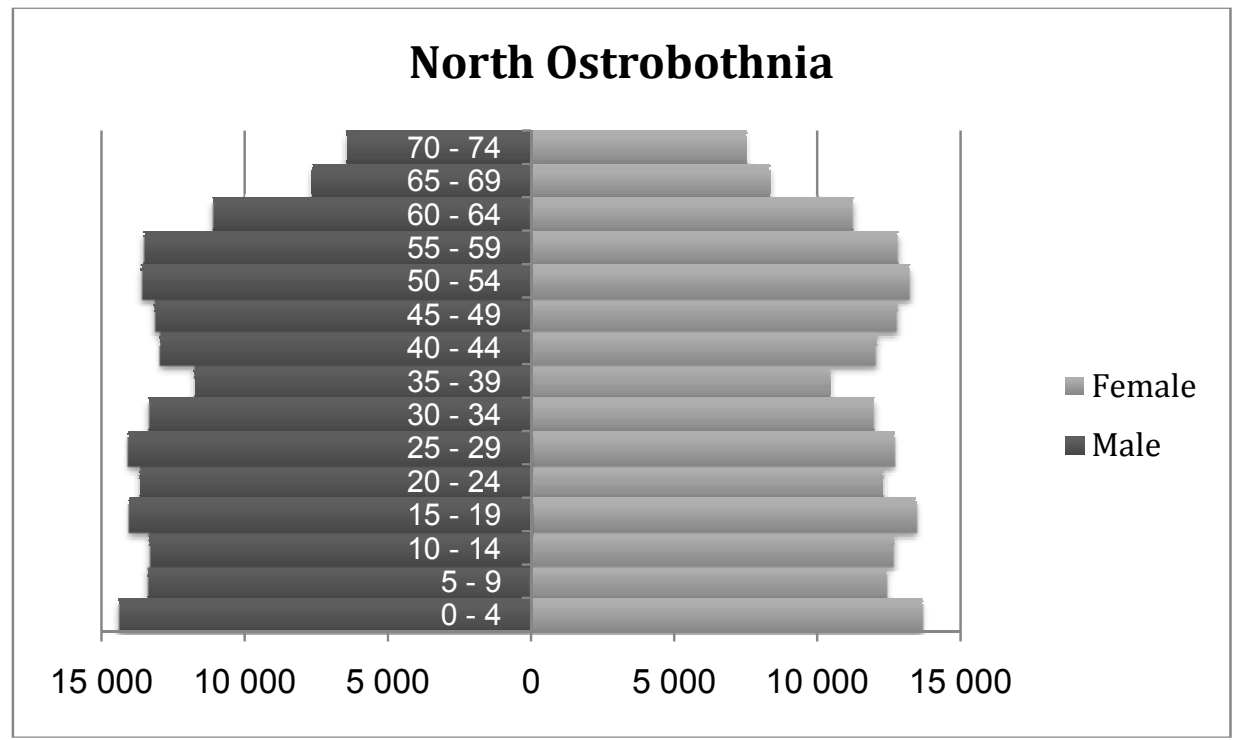

Figure $2 \mathrm{c}$

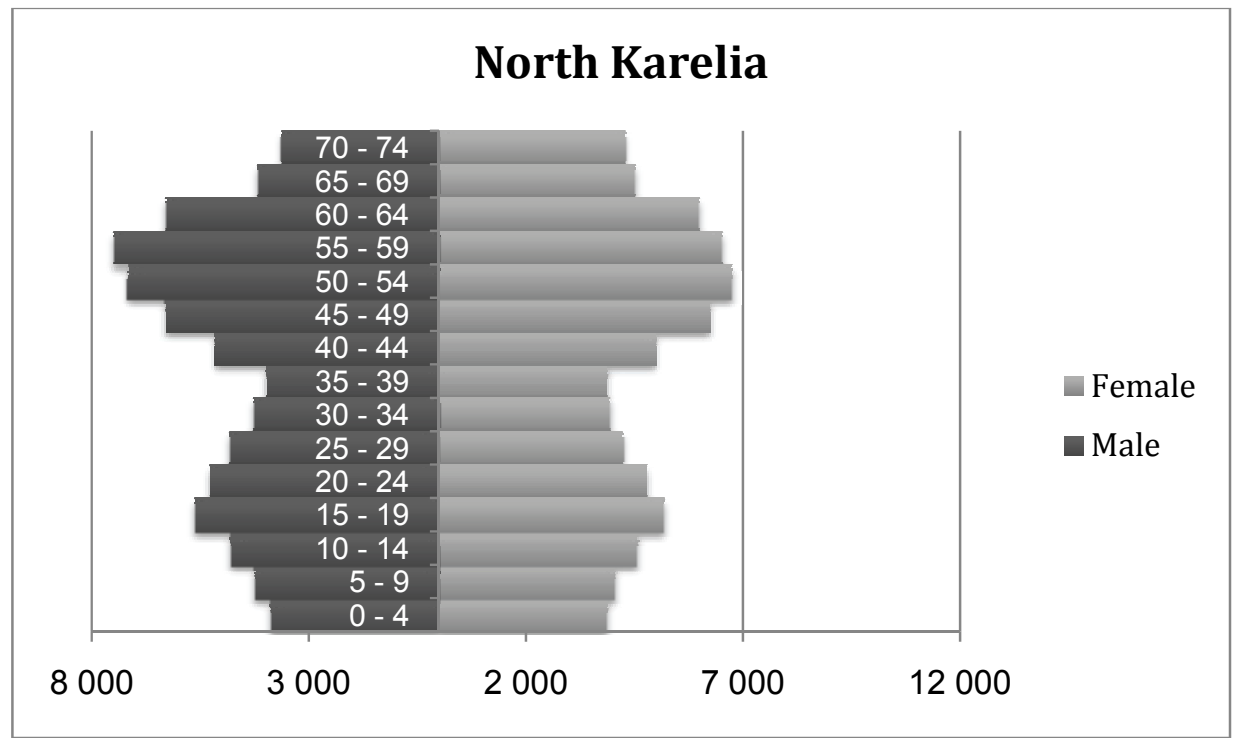

Figure 2 d. Population by gender and five-year age groups of selected NUTS 3 regions in 2008 (Statistics Finland).

(In order to be able to focus on the younger age groups and their variance the $75+$ age groups were omitted.) 

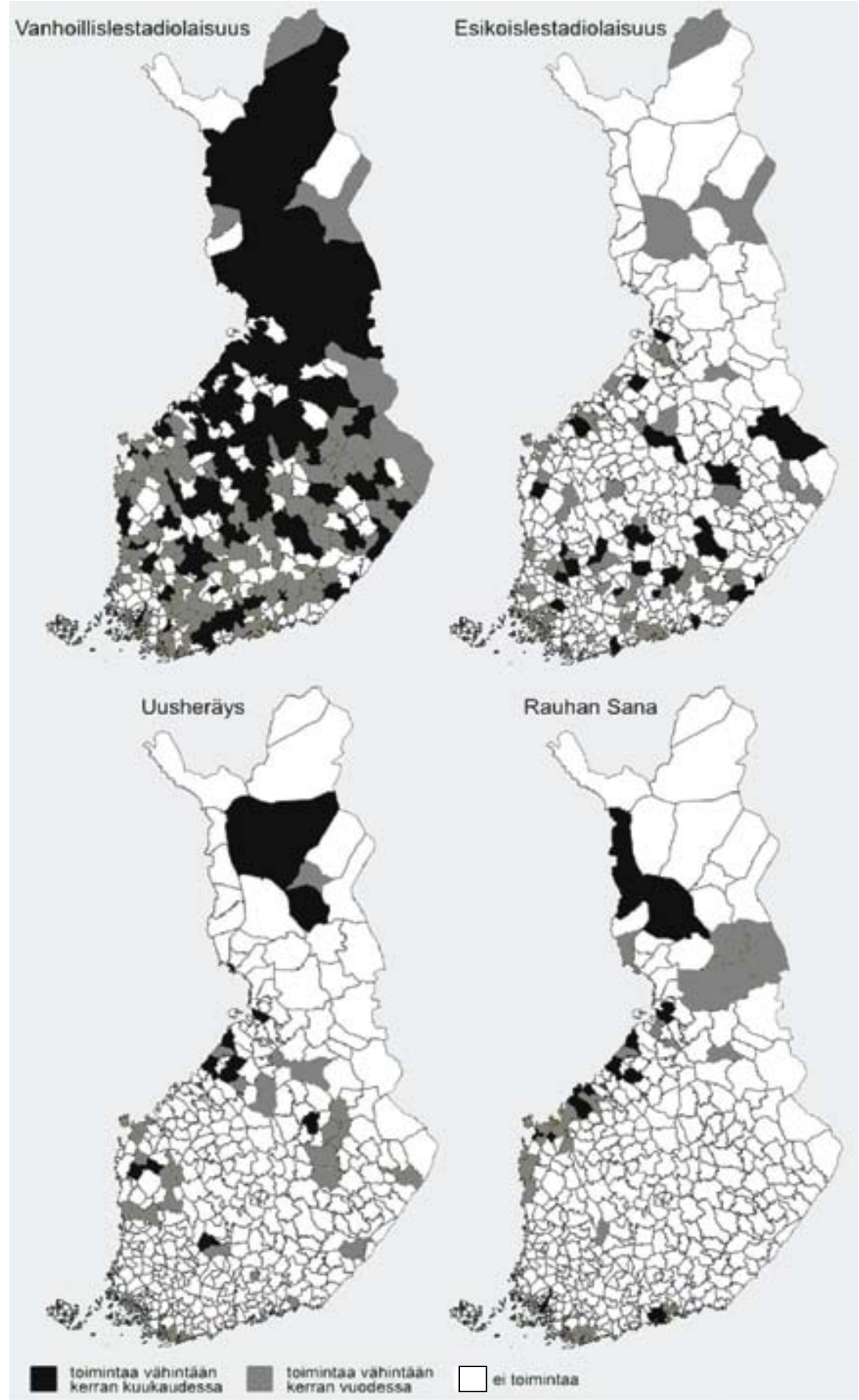

Figure 3. Map of Finnish municipalities showing Laestadian activity in (Lutheran) congregations by (sub)denomination. Conservative Lutherans top left. Darker color indicates more frequent activity: black - once a month; yellow - once a year; white - no activity (Kääriäinen 2007). 
Figure 3 shows the map of Finland with Laestadian activity in the congregations of the principal Lutheran church. An active region is defined by the congregation of the Lutheran church reporting collaboration activities with local Laestadians on a yearly to monthly basis, as published in the four-year report. The Laestadian movement had in 2007 reported activity in over two-thirds of all congregations, the same as in 2003 (Kääriainen 2008). The map shows, however, that the frequency of the activities varies regionally. It is strongest in the less densely populated Northern parts of the country. The black color indicates activity on a monthly basis, and is condensed to the NorthWest of Finland. This coincides with the higher fertility levels throughout (North) Ostrobothnia and Lapland.

\section{Fertility}

The total fertility rate (TFR) in Finland is not in the lowest low levels. In 2008 the reported TFR for the whole of Finland was 1.85 (Statistics Finland 2010). However, there are considerable variations in TFR across the nation. In addition to the very different population structures by region (cf. Figure 2), this adds to the regionally differing sizes of (future) cohorts. The total fertility rate exceeds replacement level, i.e. is above 2 in four of the nineteen regions. The capital region of Uusimaa precedes by one the region with the lowest TFR in Finland, Varsinais-Suomi. The difference between the lowest and highest regional TFR's is as high as 0.7 .

\section{Religious beliefs}

The "Church Monitor" survey (Kääriäinen 2007) included respondents from different branches of Laestadianism, in addition to others. The structure of the respondents was the following: $N=76$ for all Laestadians out of which $N=48$ Conservative Laestadians, and $N=2515$ others, i.e. non-Laestadians. The proportion of Laestadians partaking in the survey was between two and three percent depending on the definition (Conservative or all Laestadians). This is in line with the estimated numbers of Laestadians in the whole Finnish population. The sample was thus considered representative, albeit the total numbers were small.

Descriptive statistical analysis reveals for the sample of (Conservative, unless otherwise indicated) Laestadians a significantly higher average number of family members compared to all Laestadians and rest of the respondents, namely 4.02, compared to 3.47 and 2.48 respectively. A null-hypothesis testing on the result confirmed that the difference is statistically significant.

When asked about believing in God, 44 out of 48, i.e. 92 percent of Laestadian respondents said that they "believe in the God that the Christian faith has taught them" (Kääriäinen 2007). It is concluded that by Christian faith is here meant the teachings of the Lutheran church in general, including in this case, the branch of Laestadianism. 
Of all respondents, 39 percent believe in God. 87.5 percent of the Laestadians considered themselves as being religious, compared to 10.8 percent of all respondents. To summarize, based on the recent survey on beliefs and religiousness, the Laestadians stand out as being more religious and having, on average, bigger families.

\section{Socioeconomic factors}

Table 1. Regional household accounts in 2007 (Statistics Finland).

\begin{tabular}{|c|c|c|c|}
\hline \multirow[b]{2}{*}{ Region, NUTS 3} & \multicolumn{3}{|c|}{ Regional Accounts 2007} \\
\hline & Population & $\begin{array}{c}\text { Disposable Income } \\
\text { Household, } € \\
\text { mil. }\end{array}$ & $\begin{array}{c}\text { DI per capita } \\
€\end{array}$ \\
\hline Uusimaa & 1381282 & 27187.4 & 19683 \\
\hline Itä-Uusimaa & 94304 & 1695.3 & 17977 \\
\hline Varsinais-Suomi & 458512 & 7732.1 & 16863 \\
\hline Pirkanmaa & 474406 & 7912.7 & 16679 \\
\hline Satakunta & 228896 & 3755.3 & 16406 \\
\hline Kanta-Häme & 170701 & 2798.9 & 16397 \\
\hline Kymenlaakso & 183903 & 2992.6 & 16273 \\
\hline South Karelia & 134986 & 2183.7 & 16177 \\
\hline Ostrobothnia & 174599 & 2813.2 & 16112 \\
\hline Päijät-Häme & 199648 & 3214.9 & 16103 \\
\hline Etelä-Savo & 158677 & 2496.3 & 15732 \\
\hline Central Finland & 270169 & 4220.1 & 15620 \\
\hline Pohjois-Savo & 249185 & 3876.6 & 15557 \\
\hline South Ostrobothnia & 193700 & 3007.6 & 15527 \\
\hline Central Ostrobothnia & 70818 & 1087 & 15349 \\
\hline Lapland & 184663 & 2822.1 & 15282 \\
\hline North Ostrobothnia & 382040 & 5826.4 & 15251 \\
\hline Kainuu & 84065 & 1279.5 & 15220 \\
\hline North Karelia & 167132 & 2513.1 & 15037 \\
\hline Whole Country & 5288720 & 89986.4 & 17015 \\
\hline
\end{tabular}

In general, as a population's overall level of education rises, fertility declines, and income becomes more equally distributed (Sato et al. 2008). In order to witness possible regional variance, selected socioeconomic figures were obtained for all the regions in mainland Finland. Especially, the differences between the regions of highest and lowest TFR were compared, namely North Ostrobothnia and Varsinais-Suomi respectively.

North Ostrobothnia was recorded to suffer in 2007 a slightly higher unemployment rate than Varsinais-Suomi. However, the region roughly equals Varsinais-Suomi in levels of education attainment and self-sufficiency in the job market (Statistics Finland 2010). It is said that asset disposal and acquirement is jointly determined with reproduction decisions (Cigno and Rosati 1996). Considering financial indicators at household level, the Disposable Income (DI) is chosen as the most relevant measure for the purpose 
of this study, in order to have a measure for relating income with fertility (see Table 1 , sorted in order of descending DI per capita). It can be noted that in terms of DI per capita, the two regions with greatest difference in TFR are quite far from each other. However, at the same time, three other Finnish regions lowest in DI per capita share below replacement level fertility. Sato et al. (2008) find that parents with a lower level of human capital decide to have more children and invest less in education. In this study, the expectation that low DI per capita couples to higher parity, is not true for the Finnish regions in general.

It should also be noted that family size has a definite impact on DI per capita. The other way around, personal income may be less dependent on family size than disposable income (see Shields and Tracy 1986). However, both personal and disposable income are, to different extents, endogenous with family size because women's market earnings might fall with increased family size (Shields and Tracy 1986), and definitely do so in the case of many Laestadian families. The relatively low expected economic return on education to women may also be relevant, where women anticipate staying at home rather than working outside it (Voas 2007). Women may thus advance the statistics on level of human capital, but not contribute fully to the family's disposable income. In terms of regional differences, one would expect the single bread-winner communities to stand out but not necessarily to couple to high parity.

Regression analysis

Figure 4 a-c. Regression plots of the Regional proportion of Laestadians versus Total Fertility Rate (a), share of families with 4+ underaged children (b) and share of families with $3+$ children under 7 years old (c).

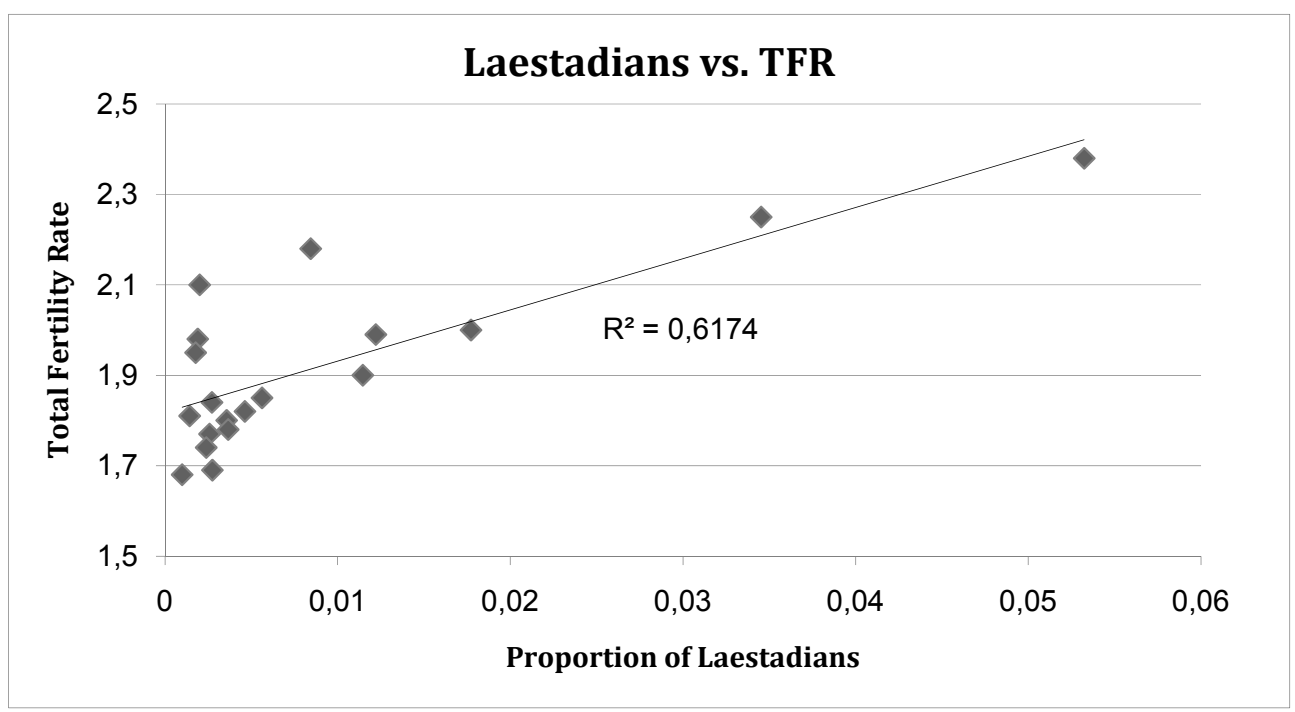




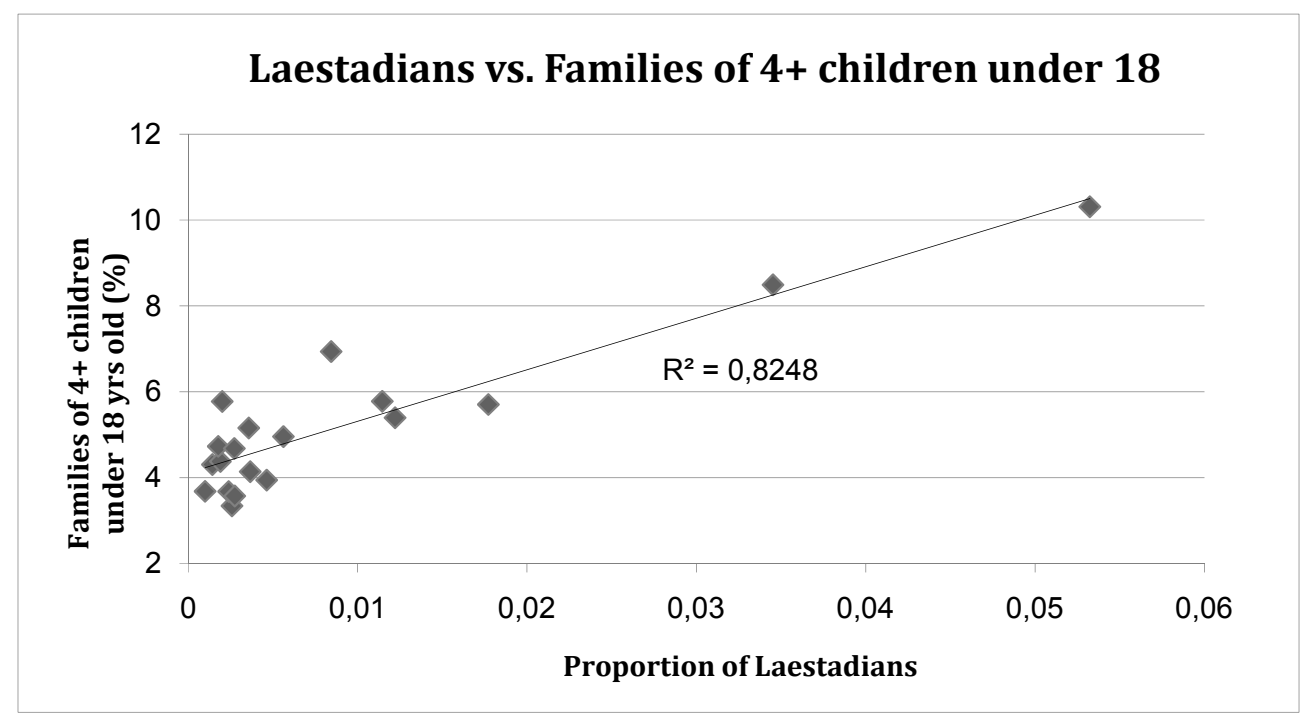

Figure $4 \mathrm{~b}$

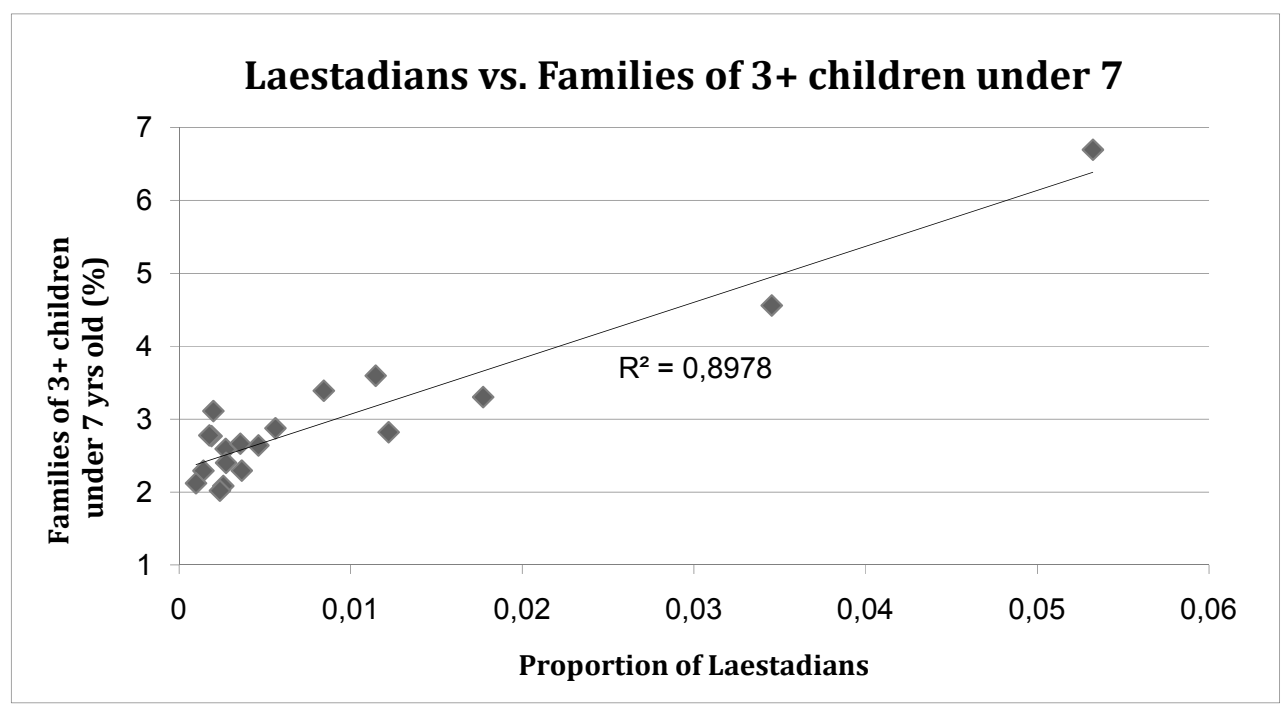

Figure $4 \mathrm{c}$

In Figure 4, the family measures of the nineteen regions are correlated against estimated Laestadian ratio in the adult population. This is quantified as the proportion of (active) adults in local congregations with respect to all adults (age $>15)$ in the region. It is found that the regression gives progressively better results moving from TFR (Figure $4 \mathrm{a}$ ) to the occurrence of big families (Figure $4 \mathrm{~b}$ ), and along to the occurrence of $3+$ children under the age of seven in the same family (Figure $4 \mathrm{c}$ ). Thus, Laestadian 
activity in a region is strongly correlated with higher TFR, big families, and many young children. Changing the dependent variable to unemployment or (lack of) education, no clear connection is found with Laestadian-rich regions, as witnessed by insignificant R-squared values $(<0.1)$ as well as weak Pearson and 1-tailed Sig. correlations (figures not shown). The variables thus have no linear relationship, unlike the family size and TFR statistics analyzed above. Simple socioeconomic correlations can thus be ruled out as the main explanatory factor for the demographic findings.

\section{Discussion}

The study of Finnish regional demography has shown strong correlations between Conservative Laestadians and fertility on the one hand and family size on the other. The results support the fact that the Laestadian religious activity is abundant, but not confined to just a few regions in the country, North Ostrobothnia being the region of most activity. The same regions are shown to exhibit distinctive demographic variance compared to the rest of Finland. It is concluded that the geographical proximity of the community may emphasize the individual's tendency to comply to the standards and recommendations provided by the community, as observed earlier by Finnäs (1991). High fertility behaviour is given as an example of such compliance.

It is seen that the geographical concentration of a high-fertility population can have an effect on the demographics of the area. Based on this particular case study of a religious minority, religion can still have a major impact on the local level in terms of population structure, and therefore long-term viability. Small-scale, local level trends can be visible even on the regional level in terms of demography, and that religion, when coupled to religiosity and high fertility, can be a predictive factor in regional development. Here religiosity does not imply, nor correlate with a distinctively (lower) socioeconomic status, nor does the fertility behaviour result from such a status.

Shields and Tracy (1986) analyse the effect of gender roles and income on family size as follows:

"...the expanded opportunities for women in markets and education may permanently alter the effects of changing income and age structure on fertility. If there is to be a dominant new theme, it may concern the effect of changing gender roles on the composition of household activities. These activities may be becoming more diversified partly because the implicit cost of time rises with income inducing families to substitute goods for time in their activities. These substitutions may be altering the role of the family from a producer of child-rearing activities to a producer and consumer of a more diversified menu of activities. A rise in relative income may not result in a rise in family size if larger families do not enhance the family's enjoyment of this more diversified set of activities. The family might have to shift its focus back towards child rearing in order to benefit from more children." 
The high emphasis on family values of the Laestadian community can be seen as a counter-trend to the ongoing "de-genderization" of breadwinning and household roles. It is unsurprising that in order to in fact enjoy having bigger families, a lot of emphasis is placed on child rearing in the Laestadian community, resulting in one parent staying at home. Concomitantly, religious values are known to matter most when the religious institutions have the mechanisms to promote compliance and punish nonconformity (McQuillan 2004). This could, in the case of Laestadians, be seen as a finger pointing at the practise of natural fertility, a topic much debated in incognito chatrooms as well as pages of newspapers and magazines in Finland. However, the conclusion is mostly drawn that common guide-lines are as significant a part of religiousness, as adhering to them is to being a member.

Religious affiliation is widely accepted as a demographic variable, still the quality and reliability of data on religious commitment is questionable (Voas 2007). In this study, the applied survey on religious beliefs was of good quality overall, however the sample size applied to Laestadians was small. Statistics on religious beliefs and activities are often far apart and difficult to find, even more so on small spatial scales. Therefore it is unsurprising that little research has been done based on religiousness and regional, much less local differences in demographic trends, in addition to religious minority status. The study of fertility differentials and minorities thus calls for innovative approaches, and an open-minded classification of players.

The study of beliefs and attitudes in demography can benefit immensely from detailed, geographically sensitive studies, and the inclusion of religion as a source of common views, and consequently distinctive demographic features. Religion, and religiosity in particular play a role in life style choices, and can thus have a strong effect on fertility events. By nature, religion seems to be a localized attribute, and thus very well applicable to small scale population studies. Further work on the topic may include small-scale population projections, and comparative studies of the contemporary fertility behaviour of minority communities in different parts of the world.

\section{Acknowledgements}

The author would like to thank the Academy of Finland for support, Anna-Maria Isola for comments, and Vegard Skirbekk for inspiration.

\section{References}

Adsera, Alicia. 2006. Religion and Changes in Family-Size Norms in Developed Countries. Review of Religious Research 47(3): 271-286.

Cigno, Alessandro and Furio C. Rosati. 1996. Jointly determined saving and fertility behaviour: Theory, and estimates for Germany, Italy, UK and USA. European Economic Review 40:1561-1589. 
Derosas, Renzo and Frans van Poppel (Eds.) 2006. Religion and the Decline of Fertility in the Western World. Dordrecht: Springer. 319 p.

Ericksen, Julia A., Eugene P. Ericksen, John A. Hostetler and Gertrude E. Huntington. 1979. Fertility Patterns and Trends Among the Old Order Amish. Population Studies 33(2): 255-276.

Espenshade, Thomas J. 1971. A New Method for Estimating the Level of Natural Fertility in Populations Practicing Birth Control. Demography 8(4): 525-536.

Frejka, Tomas and Charles F. Westoff. 2006. Religion, Religiousness and Fertility in the U.S. and in Europe. MPIDR Working Paper WP2006-013. Accessed March 23, 2010. Available online at http://www.d.umn.edu/ okuhlke/Fall\%202006\%20 Classes/GEOG\%203762\%20Europe/Readings/Week\%2013\%20-\%20Demography/ EUdemogr1.pdf

Goldscheider, Calvin and Peter R. Uhlenberg. 1969. Minority Group Status and Fertility. The American Journal of Sociology 74(4): 361-372.

Goujon, A., V. Skirbekk, K. Fliegenschnee. 2007. New times, old beliefs: Investigating the future of religions in Austria and Switzerland. Pages 355-370 in Work Session on Demographic Projections, Bucharest, 10-12 October 2007. Luxembourg: Office for Official Publications of the European Communities, Eurostat Methodologies and Working Papers.

Finnäs, Fjalar. 1991. Fertility in Larsmo: The effect of Laestadianism. Population Studies 45(2): 339-351.

Van Heek, F. 1956. Roman-Catholicism and Fertility in the Netherlands: Demographic Aspects of Minority Status. Population Studies 10(2): 125-138.

Heikkilä, Elli and Maria Pikkarainen. 2010. Research Note: Differential Population Development in the Regions of Finland Population. Space and Place 16:323334.

Kääriäinen, K. 2007. Kirkkomonitor 2004 [Church Monitor 2004] FSD2257, V1.0. Kirkon tutkimuskeskus. Tampere: Yhteiskuntatieteellinen tietoarkisto.

Kääriäinen K., K. Ketola, K. Niemelä, H. Palmu and H. Salomäki 2008. Monikasvoinen kirkko: Suomen evankelis-luterilainen kirkko vuosina 2004-2007 [The multifaceted church: Finnish Evangelic-Lutheran church in 2004-2007]. Kirkon tutkimuskeskuksen julkaisuja 103. Tampere.

Lohi, S. 1997. Pohjolan kristillisyys. Lestadiolaisuuden leviäminen Suomessa 1870 1899. [Christianity in the North. The spreading of Laestadianism in Finland in 1870-1899] Suomen Rauhanyhdistyksen Keskusyhdistys (SRK) Jyväskylä. Diss.

Lutz, W., Kritzinger, S., and V. Skirbekk. 2006. The demography of growing European identity. Science 314: 425.

McQuillan, K. 2004. When does religion influence fertility? Population and Development Review 30(1): 25-56.

McQuillan, Kevin. 2006. The evolution of religious differences in fertility: Lutherans and Catholics in Alsace, 1750-1860 In: Religion and the Decline of Fertility in the Western World, pp. 133-146. Dordrecht: Springer.

Mosher, W.D., L.B. Williams and D.P. Johnson 1992. Religion and Fertility in the United States: New Patterns. Demography 29(2): 199-214. 
Mott, Frank L. and Joyce C. Abma. 1992. Contemporary Jewish Fertility: Does Religion Make a Difference? Contemporary Jewry 13:74-94.

Muñoz, Sarah-Anne. 2009. Geographies of Faith: The Differing Residential Patterns of the Indian-Hindu, Indian-Sikh and Indian-Muslim Populations of Dundee and Glasgow. Population. Space and Place. Doi: 10.1002/psp.550.

Neuman, S. 2007. Is fertility indeed related to religiosity? A note on: 'Marital fertility and religion in Spain, 1985 and 1999'. (Population Studies 60(2): 205-221 by Alicia Adsera), Population Studies 61(2): 219-224.

Obermeyer, Carla Makhlouf 1992. Islam, Women and Politics: The Demography of Arab Countries. Population and Development Review 18(1): 33-60.

Obermeyer, Carla Makhlouf 1994. Reproductive Choice in Islam: Gender and State in Iran and Tunisia. Studies in Family Planning 25(1): 41-51.

Philipov, D. and C. Berghammer. 2007. Religion and fertility ideals, intentions and behaviour: A comparative study of European countries. Vienna Yearbook of Population Research 2007, pp. 271-305. Accessed March 24, 2010. Available online at http://hw.oeaw.ac.at/0xc1aa500d 0x0017f0e5.pdf

Sato, Yasuhiro, Ken Tabata and Kazuhiro Yamamoto. 2008. Technological progress, income inequality, and fertility. Journal of Population Economics 21(1): 135-157.

Shields, Michael P. and Ronald L. Tracy. 1986. Four Themes in Fertility Research. Southern Economic Journal 53(1): 201-216.

SRK 2010. Central Committee of Conservative Laestadian Congregations (SRK), personal communication.

Statistics Finland. 2010. PX-Web-Databases. Accessed Sep 14, 2010. Available online at: http://pxweb2.stat.fi/database/StatFin/databasetree fi.asp.

Voas, D. 2007. Does religion belong in population studies? Environment and Planning A 39: 1166-1180.

Zhang, Li. 2008. Religious affiliation, religiosity, and male and female fertility. Demographic Research 18:233-262. Accessed March 24, 2010. Available online at http://www.demographic-research.org/volumes/vol18/8/18-8.pdf

\section{Appendix}

\section{Regression and correlation analysis}

Simple linear regression was carried out for the regionally estimated proportion of Laestadians as the dependent variable. The following independent variables (IV) were chosen: \%[Families with 3+ children under the age of 7]; \%[Families with 4+ children under the age of 18]; Total Fertility Rate (TFR). Municipal population, age $>15$, from 2009 (Statistics Finland 2010) was aggregated to regional level, as was the data on Laestadian congregation sizes (SRK 2010) to obtain the variable "Proportion of Laestadians" indicating the proportion of those belonging to a Laestadian congregation with respect to the total adult (age $>15$ ) population. In order to sustain a close to ideal cases-to-IV ratio (19:1), the simple linear regression method was chosen over a multiple regression analysis. Table A.1 summarizes the used data. Table A.2 gives the 
bivariate correlations of further socioeconomic variables mentioned in the document text. Results indicate no significant correlations between the chosen variables and Laestadians for the 19 regions.

Table A.1

\begin{tabular}{lrcccc}
\hline 2008 & Population & \multicolumn{3}{c}{ Share of } \\
Region & > age 15 & Laestadians & 4+ families & 3+ families & TFR \\
\hline Central Finland & 226273 & 0.0115 & 5.78 & 3.60 & 1.90 \\
Central Ostrobothnia & 57723 & 0.0345 & 8.49 & 4.56 & 2.25 \\
Etelä-Savo & 76040 & 0.0014 & 4.31 & 2.29 & 1.81 \\
Itä-Uusimaa & 70523 & 0.0019 & 4.38 & 2.77 & 1.98 \\
Kainuu & 143627 & 0.0122 & 5.40 & 2.82 & 1.99 \\
Kanta-Häme & 155266 & 0.0018 & 4.73 & 2.78 & 1.95 \\
Kymenlaakso & 154923 & 0.0024 & 3.68 & 2.02 & 1.74 \\
Lapland & 306770 & 0.0177 & 5.71 & 3.30 & 2.00 \\
North Karelia & 140694 & 0.0036 & 5.16 & 2.66 & 1.80 \\
North Ostrobothnia & 209073 & 0.0532 & 10.31 & 6.70 & 2.38 \\
Ostrobothnia & 145344 & 0.0020 & 5.78 & 3.11 & 2.10 \\
Päijät-Häme & 169020 & 0.0027 & 4.68 & 2.59 & 1.84 \\
Pirkanmaa & 401729 & 0.0046 & 3.94 & 2.64 & 1.82 \\
Pohjois-Savo & 192097 & 0.0056 & 4.96 & 2.88 & 1.85 \\
Satakunta & 160048 & 0.0037 & 4.14 & 2.30 & 1.78 \\
South Karelia & 114799 & 0.0026 & 3.34 & 2.09 & 1.77 \\
South Ostrobothnia & 134157 & 0.0084 & 6.94 & 3.39 & 2.18 \\
Uusimaa & 1166942 & 0.0027 & 3.57 & 2.40 & 1.69 \\
Varsinais-Suomi & 387273 & 0.0010 & 3.68 & 2.12 & 1.68 \\
\hline
\end{tabular}

Based on data by Statistics Finland (2010)

Table A.2

\begin{tabular}{llc}
\hline 2007 & & Laestadian members \\
\hline \multirow{3}{*}{ Disposable Income } & Pearson Correlation & .191 \\
& Sig. (2-tailed) & .434 \\
& $\mathrm{~N}$ & 19 \\
\hline \multirow{4}{*}{ Laestadian members } & Pearson Correlation & 1 \\
& Sig. (2-tailed) & \\
& $\mathrm{N}$ & 19 \\
\hline \multirow{3}{*}{ Education (index) } & Pearson Correlation & .388 \\
& Sig. (2-tailed) & .101 \\
& $\mathrm{~N}$ & 19 \\
\hline \multirow{3}{*}{ Unemployment } & Pearson Correlation & .182 \\
& Sig. (2-tailed) & .457 \\
& $\mathrm{~N}$ & 19 \\
\hline
\end{tabular}

